\title{
Plágio no meio educacional e as medidas que vêm sendo adotadas para combatê-lo no Brasil: uma Revisão Sistemática da Literatura
}

Danielle dos Santos Veloso da Costa, ICT/Unifesp, danielle.veloso@unifesp.br Tiago de Oliveira, ICT/Unifesp, tiago.oliveira@unifesp.br

Resumo: O crescimento da internet e do uso de dispositivos com acesso à web ampliou o acesso às fontes de pesquisa, facilitando a existência de plágio no ensino. Este artigo apresenta uma Revisão Sistemática da Literatura (RSL), com o objetivo de construir uma visão geral dos estudos que tratam de plágio no meio educacional no Brasil e as medidas que estão sendo adotadas para combatê-lo nos últimos 10 anos. A análise da revisão sistemática mostrou que, em sua maioria, têm sido publicado estudos sobre plágio no ensino superior e que a principal estratégia adotada para combatê-lo, no meio educacional, é por meio da detecção via software em textos ou em códigos fonte. Os resultados apresentados apontam para a necessidade de mais estudos voltados para estratégias que utilizam o ensino para combater o plágio, o que propiciaria uma exploração e desenvolvimento de novas aplicações envolvendo o tema.

Palavras-chave: Plágio Acadêmico, Meio Educacional, Combate ao Plágio.

\section{Plagiarism in the educational environment and the measures that have been adopted to combat it in Brazil: A Systematic Review of Literature}

Abstract: The growth of the internet and the use of devices with access to the web has increased the access to the sources of research, facilitating the existence of plagiarism in the teaching. This article presents a Systematic Review of Literature (SRL), with the objective of constructing an overview of the studies that deal with plagiarism in the educational environment in Brazil and the measures that have been adopted to combat it in the last 10 years. The analysis of the systematic review showed that most studies have been published on plagiarism in higher education and that the main strategy adopted to combat it in the educational environment is through software detection in texts or in source codes. The results presented point to the need for more studies focused on strategies that use teaching to combat plagiarism, which would allow the exploration and development of new applications involving the theme.

Keywords: Academic Plagiarism, Educational Environment, Fight Against Plagiarism.

\section{Introdução}

Diante da popularização dos dispositivos com acesso à Web e da enorme expansão da Internet, ampliando a disponibilidade das fontes de pesquisas, as pessoas passaram a ter acesso as mais diversas informações. Isso fez com que as pesquisas acadêmicas se tornassem mais fáceis, facilitando a existência de plágio no ensino (De Oliveira Araújo, 2017).

O plágio, também conhecido como apropriação indevida de obra ou conteúdo alheio, que é apresentado como sendo próprio, está relacionado diretamente ao cotidiano acadêmico (Krokoscz, 2014). Neste contexto, a grande quantidade de atividades, alunos e turmas, além do desenvolvimento constante e progressivo dos alunos, especialmente quando inseridos no mundo virtual, torna muito difícil, ou mesmo impossível, para o professor, o acompanhamento adequado dos trabalhos a ele entregues. Com isso, o plágio tem se tornado uma prática comum e muito difícil de ser combatida.

Como descrito na cartilha sobre plágio acadêmico, criada pela Comissão de Avaliação de Casos de Autoria, da Universidade Federal Fluminense, "O plágio 
acadêmico se configura quando um aluno retira, seja de livros ou da internet, ideias, conceitos ou frases de outro autor (que as formul ou e as publicou), sem lhe dar o devido crédito, sem citá-lo como fonte de pesquisa" (Nery et al., 2010). Existem vários tipos de plágio no meio acadêmico. Krokoscz (2014) define os tipos mais comuns de plágio, que são: plágio direto - copiar do texto, sem usar aspas e sem referenciar a fonte; plágio indireto - copiar um texto, realizando pequenas alterações nele; plágio Mosaico - copiar partes de textos de várias fontes e mistura -los; plágio consentido - apresentar um trabalho feito por outro como sendo seu; plágio de chavão - copiar expressões ou frases de efeito de outros autores; plágio de fontes - inserir citações ao trabalho sem consultar a fonte; autoplágio - apresentar o mesmo trabalho em outras circunstâncias.

No Brasil, as instituições de ensino e vários órgãos ligados ao governo têm se preocupado com o plágio no meio educacional. $\mathrm{O}$ Conselho Nacional de Desenvolvimento Científico e Tecnológico (CNPq), também preocupado com o crescente histórico de fraudes em publicações científicas, criou, em 2012, a Comissão de Integridade na Atividade Científica. As atribuições desta instituição, de m aneira geral, são: coordenar, nacionalmente, ações preventivas e educativas sobre a integridade das pesquisas realizadas e/ou publicadas. Na página do $\mathrm{CNPq}$, está descrito um conjunto de diretrizes básicas para a integridade na atividade científica: "Diretrizes - Portal CNPq". Além do CNPq, a Fundação de Amparo à Pesquisa do Estado do São Paulo (FAPESP) também divulgou documentos normativos sobre este tema. Isso indica que há uma preocupação, ainda que recente, sobre a ética e a má conduta no meio científico no país (Vilaça, 2015).

Considerando a importância do ensino sobre plágio para os alunos, com base nas considerações feitas anteriormente, foi realizada uma RSL, com o objetivo de construir uma visão geral dos estudos que tratam de plágio no meio educacional no Brasil e as medidas que estão sendo adotadas para combatê-lo.

O artigo está organizado em quatro seções, nesta seção é apresentada a Introdução.

Na seção 2 é apresentado a Metodologia de pesquisa. A seção 3 descreve os Resultados e discussões, apresentando uma visão geral da pesquisa e a análise das questões de pesquisa e a seção 4 apresenta a Conclusão.

\section{Metodologia de Pesquisa}

A metodologia de pesquisa para conduzir a RSL foi baseada nas diretrizes propostas por Kitchenham (2007). Nesta seção, foram definidas as questões que se deseja esclarecer com a pesquisa, a String de busca, os critérios de inclusão e exclusão dos artigos e a extração dos dados.

\subsection{Questões de Pesquisa}

Com o objetivo de fornecer uma visão geral dos estudos que, no meio educacional no Brasil, vêm sendo conduzidos a respeito de plágio, foram formuladas as Questões de Pesquisa (QP), as quais podem ser visualizadas a seguir: QP1: Como estão distribuídos os estudos sobre plágio no meio educacional? QP2: Em qual nível educacional o estudo sobre plágio tem sido aplicado? QP3: Quais são as estratégias que têm sido adotadas para combater o plágio? QP4: Quais são as vantagens, desvantagens e problemas em relação as estratégias usadas para combater o plágio a cadêmico que vêm sendo reportada s na literatura?

\subsection{Estratégia de busca}

A estratégia de busca foi separada em 2 etapas: (1) definição das palavras-chave e String de busca; (2) determinação das bases bibliográficas, revistas e conferências que 
foram usadas. Na primeira etapa, foram definidas quais são as palavras-chave para a proposta de revisão, sendo: Plágio, detecção, ensino (educação, aprendizado). As palavras-chave e seus sinônimos, definidos através das perguntas de pesquisa, geraram a seguinte String de busca: 'plágio' AND ('detecção' OR 'ensino' OR 'educação' OR 'aprendizado'). Na próxima etapa foram selecionadas 19 bases de dados que atenderam aos critérios de disponibilidade dos artigos nas bases de dados bibliográficas e de disponibilidade de buscas a partir da String de busca. As bases de dados selecionadas foram: Google Acadêmico, Periódicos Capes, Revista Brasileira de Educação (RBE), Revista Novas Tecnologias na Educação (RENOTE), Revista Brasileira de Informática na Educação (RBIE), Simpósio Brasileiro de Informática na Educação (SBIE), Workshop de Desafios da Computação Aplicada à Educação (DESAFIE), Workshop de Informática na escola (WIE), Workshop do Congresso Brasileiro de Informática na Educação (CBIE), Revista Eletrônica em Gestão, Educação e Tecnologia Ambiental (REGET), Revista Conhecimento em Ação (RCA), Revista Ponto de Acesso (RPA), Revista Bioética (RBIO), Revista de Direito Inovação, Propriedade Intelectual e Concorrência (RDIPIC), Revista Brasileira de Aprendizagem Aberta e a Distância (RBAAD), Revista Informação e Sociedade( I\&S), Revista Brasileira de Ensino de Ciência e Tecnologia ( RBECT), Revista Tempos e Espaços (RTEE) e Journal of Health Informatics (JHI). No Google Acadêmico utilizamos a String de busca e verificamos os resultados das 10 primeiras páginas retornadas. Nos periódicos e anais de eventos selecionados as buscas foram feitas em seus respectivos portais, porém percebeu -se que durante as pesquisas iniciais, a String de busca retornava um número menor de resultados relevantes quando comparado com a busca utilizando somente a palavra-chave plágio. Por isso, optou -se por fazer as buscas nas bases dos periódicos e eventos utilizando somente a palavra-chave plágio. Os últimos acessos às bases de dados foram realizados entre janeiro e março de 2019.

\subsection{Seleção dos estudos}

Com o objetivo de melhorar os resultados obtidos, foram criados critérios de inclusão e exclusão, com base nas perguntas de pesquisa. Os critérios de inclusão e exclusão, apresentados na Quadro 1, foram aplicados aos 204 artigos selecionados.

Quadro 1 - Critérios de inclusão e exclusão

\begin{tabular}{|l|l|}
\hline \multicolumn{1}{|c|}{ Critérios de Inclusão } & \multicolumn{1}{c|}{ Critérios de Exclusão } \\
- Revisados por especialistas que forneçam & - Artigos duplicados; \\
respostas para as perguntas de pesquisa; & - Artigos resumidos, livros, monografias, dissertações \\
- Tratam sobre o tema plágio no meio acadêmico; & e teses; \\
- Apresentam estratégias adotadas para combater o & - Envolvem plágio sem objetivos educacionais; \\
plágio; & - Não estejam relacionados às questões de pesquisa; \\
- Publicados a partir do ano de 2008 (10 anos); & - Não estejam escritos em português; \\
- Publicados em conferências e periódicos. & - Não estejam disponíveis integralmente nas bases de \\
& dados pesquisadas. \\
\hline
\end{tabular}

Em seguida, após organizar os 204 artigos recuperados das bases de dados, excluídos os estudos que claramente não estavam relacionados ao tema da pesquisa e que não atendiam aos critérios de inclusão, 59 artigos foram considerados para extração de dados (para mais detalhes sobre as referências bibliográficas encontradas da RSL, consultar o seguinte endereço eletrônico: https://bit.ly/2SBfVEq). O Quadro 2 apresenta o resultado geral da busca realizada nas bases de dados.

Quadro 2 - Resultado geral da busca. 


\begin{tabular}{|c|c|c|c|c|c|c|c|c|c|c|c|c|c|c|c|c|c|c|c|c|}
\hline $\begin{array}{c}\text { Bases de } \\
\text { dados }\end{array}$ & 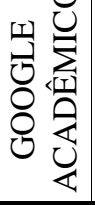 & $\underset{0}{\frac{n}{2}}$ & $\frac{1}{2}$ & 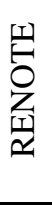 & $\stackrel{\varphi}{\oplus}$ & $\stackrel{\omega}{\oplus}$ & 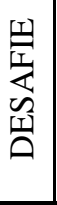 & $\stackrel{11}{3}$ & 貦 & 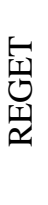 & $\underset{\simeq}{\longleftarrow}$ & $\begin{array}{l}\mathbb{a} \\
\stackrel{2}{a}\end{array}$ & $\frac{0}{a}$ & $\frac{\circlearrowright}{\underline{\underline{\rho}}}$ & $\begin{array}{l}\frac{2}{4} \\
\infty \\
\underline{a}\end{array}$ & $\ddot{z}$ & $\begin{array}{l}\tilde{U} \\
\underline{n} \\
\underline{n}\end{array}$ & 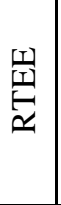 & 刍 & Total \\
\hline $\begin{array}{l}\text { Quantidade } \\
\text { de artigos }\end{array}$ & 100 & 50 & 15 & 5 & 2 & 6 & 1 & 2 & 2 & 1 & 1 & 1 & 5 & 2 & 1 & 3 & 3 & 3 & 1 & 204 \\
\hline $\begin{array}{l}\text { Artigos } \\
\text { incluídos }\end{array}$ & 23 & 6 & 3 & 5 & 2 & 5 & 1 & 1 & 1 & 1 & 1 & 1 & 3 & 1 & 1 & 1 & 1 & 1 & 1 & 59 \\
\hline
\end{tabular}

\subsection{Extração dos dados}

A extração de dados foi realizada através de planilhas que auxiliaram o processo de extração de informações dos artigos selecionados. A partir dos artigos, foi possível extrair algumas informações gerais, como: ano de publicação, tipo dos artigos e IES que publicaram estudos sobre o tema. Além disso, extraímos as respostas para as questões de pesquisa. Para as questões QP1, QP2 e QP3, definiu -se uma lista de valores ou opções possíveis, como descrito nas seções 2.4.1, 2.4.2 e 2.4.3. Para a questão QP4, as informações necessárias para respondê-la foram compiladas diretamente dos estudos analisados. Cada QP será explicada nas subseções seguintes.

\subsubsection{Método de pesquisa}

Para responder à primeira questão de pesquisa, os estudos foram separados de acordo com o método de pesquisa. Porém, tivemos algumas dificuldades, pois, muitas vezes, os estudos não traziam claramente o método de pesquisa. Então, para estes casos, fazia-se necessário ler e interpretar os estudos. Adotamos as separações usadas por Martins; Gorschek (2016) e Unterkalmsteiner et al. (2012). Os estudos foram separados segundo os seguintes critérios de classificação quanto ao método de pesquisa: estudo de caso - quando o estudo avalia empiricamente uma abordagem ou um conceito teórico. Tem o objetivo de conhecer em profundidade determinada situação, procurando descobrir o que há de essencial e característico (Yin, 2005) (Gil, 2009); experimento - estudos que, através de experimentos, determinam um objeto de estudo, selecionam as variáveis que influenciam no experimento e define as formas de controle e de observação dos efeitos que a variável produz no objeto de estudo (Gil, 2017); análise conceitual - estudos que discutem um conceito teórico ou uma nova abordagem, mas sem validá-la; liç̃̃es aprendidas (lessons learned) - estudos que relatam as lições aprendidas; levantamento (survey) - estudos que coletam dados de um grupo de interesse com base em um questionário ou entrevista como instrumento de pesquisa (Gil, 2017); revisão - estudos que expõem ideias já discutidas por outros autores; $\boldsymbol{R S L}$ - estudos que conduzem uma revisão sistemática da literatura utilizando métodos sistemáticos para identificar, coletar e analisar os estudos;

\subsubsection{Nível educacional}

Para responder a segunda questão, separamos os estudos em relação ao nível educacional em que ele está sendo aplicado. Em alguns artigos, não conseguimos identificar dados relacionados ao nível educacional.

\subsubsection{Estratégias adotadas}

$\mathrm{Na}$ terceira questão, separamos os estudos em relação às estratégias adotadas para combater o plágio no meio educacional. Para melhor estruturar os dados obtidos, 
adotamos a organização em categorias disponível em Krokoscz (2011), sendo apresentadas no Quadro 3:

Quadro 3 - Categorização das estratégias adotadas para combater o plágio no meio educacional adaptado de Krokoscz (2011).

Medidas institucionais: 1. Página web institucional com conteúdo exclusivo sobre plágio; 2. Política Institucional sobre o plágio; 3. Guias, manuais e/ou documentos oficiais sobre o assunto; 4. Comissão de Integridade Acadêmica, Comitê Disciplinar, Sindicância, etc.

Medidas preventivas: 1 . Orientação: Ações de esclarecimentos da comunidade educativa (Definição e/ou caracterização do plágio; documentos de professores. conferências, workshops, formulários de declaração da idoneidade do trabalho, indicação de links para aprofundamento sobre o assunto; etc.); 2. Capacitação: Ações de instrumentalização, tais como cursos, atividades, exercícios, abordagem disciplinar, elaboração de manuais de escrita acadêmica, tópico de disciplina ou orientações para a elaboração de trabalhos acadêmicos; 3. Formação: Apelo a princípios e valores, ações voltadas para a importância do compromisso e desenvolvimento de princípios éticos. como a preservação da reputação do aluno.

Medidas diagnósticas: 1. Disponibilização e/ou utilização de softwares de detecção do plágio. 2. Detecção manual, análise da escrita.

Medidas corretivas: 1 . Descrição do plágio nos códigos institucionais (Código de Honra; Código de Ética etc.); 2. Penalização (advertência, suspensão, expulsão, etc.).

\subsubsection{Vantagens, desvantagens e problemas}

Na quarta questão de pesquisa, foi possível identificar as vantagens, desvantagens e os problemas a respeito das estratégias que foram adotadas para combater o plágio acadêmico. Esses dados foram retirados diretamente dos estudos, após lê-los e interpretálos. Entretanto, em alguns estudos, não foi possível identi ficar, de forma clara, a descrição dos três elementos: vantagens, desvantagens e problemas. Esses dados serão melhor detalhados na seção logo a seguir (Resultados e discussões).

\section{Resultados e discussões}

De um total de 204 estudos, 59 artigos foram selecionados, pois atingiram os critérios de inclusão. Após a leitura dos artigos, seus dados foram extraídos e analisados. Como comentado anteriormente, as referências desta RSL estão disponíveis no seguinte endereço eletrônico: https://bit.ly/2SBfVEq. Cada referência bibliográfica selecionada para análise recebeu um valor numérico decimal, correspondendo a um identificador (denominado Id) do estudo. Este identificador será utilizado no restante do artigo para citar os resultados da RSL obtidos no processo de extração.

\subsection{Visão geral dos estudos}

Antes de apresentar os resultados para cada pergunta de pesquisa, extraímos e analisamos as características gerais dos artigos incluídos nesta revisão, como ano de publicação, tipo da fonte dos artigos e distribuição dos artigos por Instituição de Ensino. Os artigos analisados foram publicados no período de 10 anos, entre 2008 a 2018. A Figura 1 apresenta a quantidade de artigos analisados por ano de publicação. De acordo com esse gráfico, o plágio no meio educacional tem sido abordado na literatura científica nacional, onde pode-se notar um aumento recente na quantidade de publicações sobre o tema. É interessante observar que, em paralelo ao aumento no número de publicações, a partir de 2010, começou a ser realizado, a partir desse mesmo ano, o Encontro Brasileiro sobre Integridade em Pesquisa, Ética na Ciência e em Publicações (BRISPE) e, no ano de 
2012, reuniu-se pela primeira vez, a Comissão de Integridade na Atividade Científica do (CNPq).

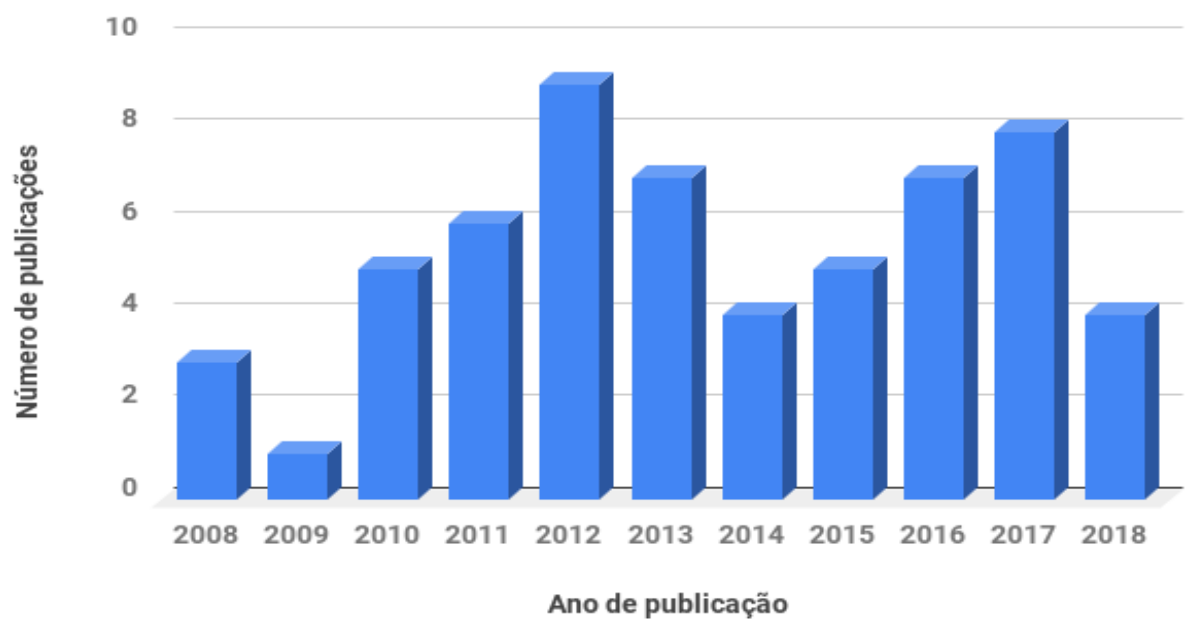

Figura 1 - Quantidade de artigos analisados por ano de publicação.

A segunda característica analisada foi com relação ao tipo de fonte dos artigos. A maioria dos artigos são documentos publicados em periódicos (83,1\%, 49 artigos) seguido por publicações em conferências (16,9\%, 10 artigos).

A última característica geral analisada foi com relação a distribuição dos artigos por Instituição de Ensino. Dentre os 59 artigos analisados, observou-se a contribuição de autores de 58 Instituições. As Instituições que se destacaram foram a Universidade Federal de São Paulo (USP), com 6 publicações, Universidade Federal de Santa Maria (UFSM), com 5 publicações, seguida pelas Universidade Federal do Ceará (UFC), Universidade Federal do Rio Grande do Sul (UFRGS), Universidade Federal do Alagoas (UFAL), Universidade Federal de Campina Grande (UFCG) e Universidade Federal de Pernambuco (UFPE) ambas com participação em 3 artigos cada. As Universidade Federa 1 Rural de Pernambuco (UFRPE), Universidade do Vale do Itajaí (UNIVALI), Universidade de Brasília (UNB), Centro Universitário UNIVATES, Fundação Getúlio Vargas e Pontifícia Universidade Católica do Rio Grande do Sul (PUCRS) com participação em 2 artigos cada. As outras Instituições tiveram uma publicação cada.

\subsection{Análise das questões de pesquisa}

Após analisar as características gerais dos estudos selecionados, analisamos os dados referentes às questões de pesquisa envolvidas nesta revisão sistemática.

QP1: Como estão distribuídos os estudos sobre plágio no meio educacional? Resultado: Os estudos selecionados estão distribuídos em estudos de caso (29 artigos, $48,3 \%$ ), representados pelos identificadores (ID) $[3,4,5,7,8,9,13,18,21,25,26,27,28,29$, $32,34,38,39,41,42,43,44,45,46,49,51,52,58,59]$, análise conceitual (11 artigos, 18,3\%) $[1,14,22,31,35,37,40,50,54,55,57]$, experimento (6 artigos, $10 \%)[2,6,11,15,20,30]$, revisão (6 artigos, 10\%) [19,33,47,48,53,56], RSL (4 artigos, 6,7\%) [10,12,17,24], levantamento (3 artigos, 5\%) [16,23,36] e lições aprendidas (1 artigo, 1,7\%) [24], como pode ser visto na Figura 2. 

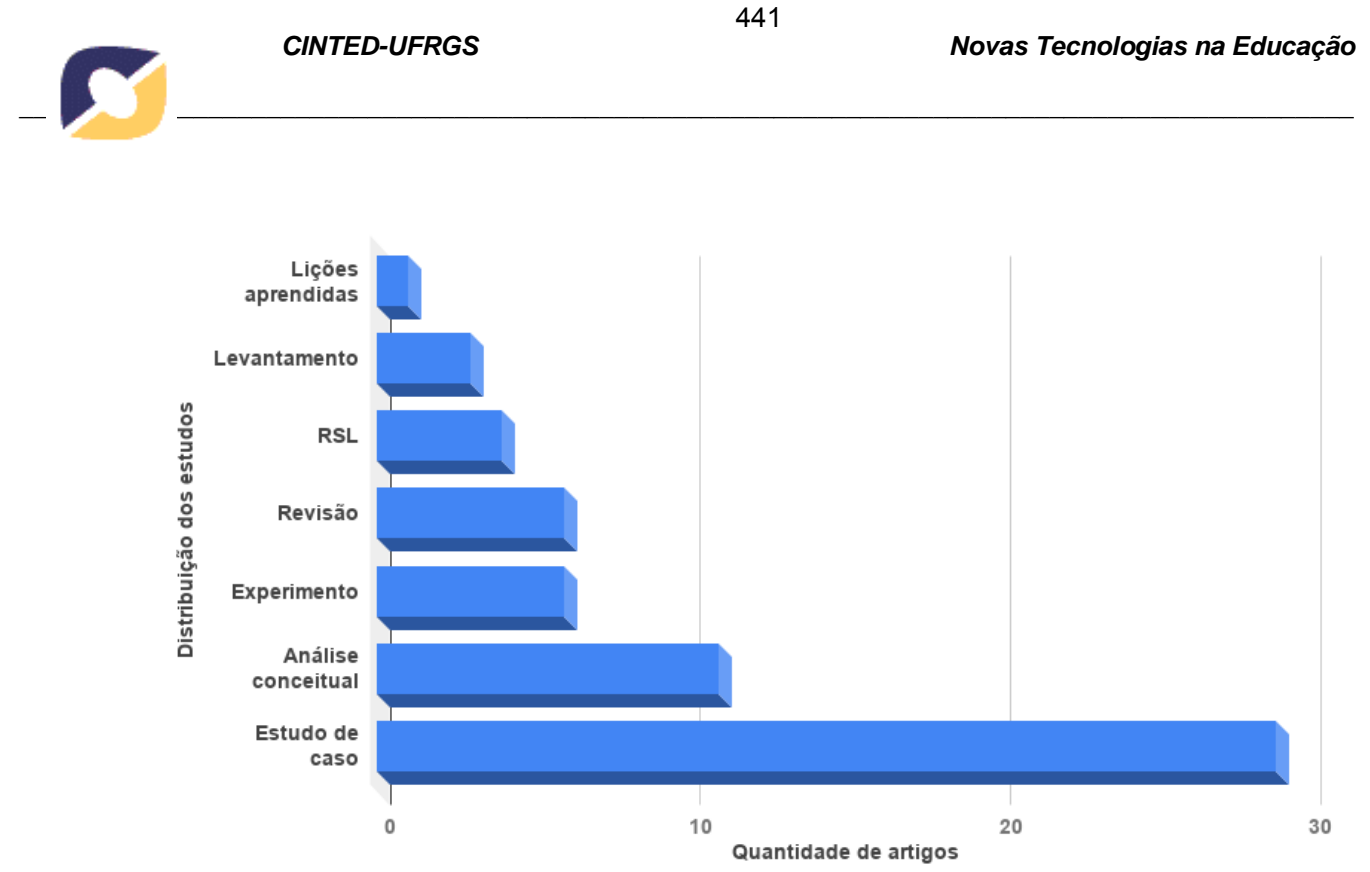

Figura 2 - Distribuição dos artigos selecionados de acordo com o método de pesquisa.

Análise e discussão: Os resultados indicam que a maioria dos estudos selecionados, para esta RSL, são estudos de caso seguido por análise conceitual. Em geral, estes estudos, selecionados e classificados como estudo de caso, foram os que reuniam informações sobre o plágio no meio educacional, a partir de múltiplas fontes de dados, como pesquisa documental ou bibliográfica [3,4,7,26,27,38,39,41,52], entrevistas (questionários) $[4,9,18,28,29,32,43,44,49,51,58]$, trabalhos/provas com subsequente verificação de ocorrência de plágio [13,20,29,34,42], observação [4,9,25,28] e grupo focal [28]. Os artigos, que utilizam como método de pesquisa o experimento, são estudos que apresentavam experimentos voltados para a implementação e/ou análise de softwares detectores de plágio [2,6,11,15,20,30].

\section{QP2: Em qual nível educacional o estudo sobre plágio tem sido aplicado?}

Resultado: No que diz respeito ao nível educacional em que o estudo sobre plágio tem sido aplicado, a maior parte corresponde à graduação (19 artigos, 32,2\%) $[4,6,7,11,13,15,16,18,23,24,25,28,29,32,36,39,44,49,51]$, em seguida, estudos que foram aplicados tanto na graduação quanto na pós-graduação (12 artigos, 20,3\%) $[3,26,27,31,33,34,35,38,46,47,48,58]$, seguido por estudos aplicados somente na pósgraduação (4 artigos, 6,8\%) [2,8,30,41]. Ainda verificamos que (2 artigos, 3,4\%) foram aplicados no ensino médio, seguido por (2 artigos, 3,4\%) [9,43] utilizado em curso de programação [20,42] e (20 artigos, 33,9\%) nos quais não se definiu o nível educacional $[1,5,10,12,14,17,19,21,22,37,40,45,50,52,53,54,55,56,57,59]$. Desta forma, somando os estudos aplicados na graduação e pós-graduação, concluímos que o tema plágio tem sido reportado majoritariamente no ensino superior (35 artigos, 59,3\%).

Análise e discussão: Ao analisarmos os resultados obtidos com a realização dessa RSL, pode-se concluir, como resposta para a questão QP2, que os estudos relacionados ao plágio têm sido praticamente aplicados apenas no ensino superior (graduação e pós graduação). Diante desse resultado, é de extrema importância que esse tema também seja estudado e aplicado em outros níveis educacionais, como, por exemplo, o ensino médio, visando uma análise mais plural e abrangendo especificidades diferentes dos ambientes acadêmicos universitários.

QP3: Quais são as estratégias que têm sido adotadas para combater o plágio?

Resultado: Após a leitura dos artigos, foi possível encontrar algumas estratégias usadas para combater o plágio no meio educacional no Brasil. Dos 59 artigos analisados, 23 artigos (39\%) citaram alguma estratégia adotada no combate ao plágio $[2,3,4,5,6,9,11,13$, $15,20,24,26,29,30,32,34,39,41,42,45,46,49,52]$. Dessa forma, utilizamos o agrupamento 
das estratégias estruturadas por Krokoscz (2011). A Figura 3 apresenta as principais estratégias adotadas para combater o plágio encontrado nos artigos selecionados.

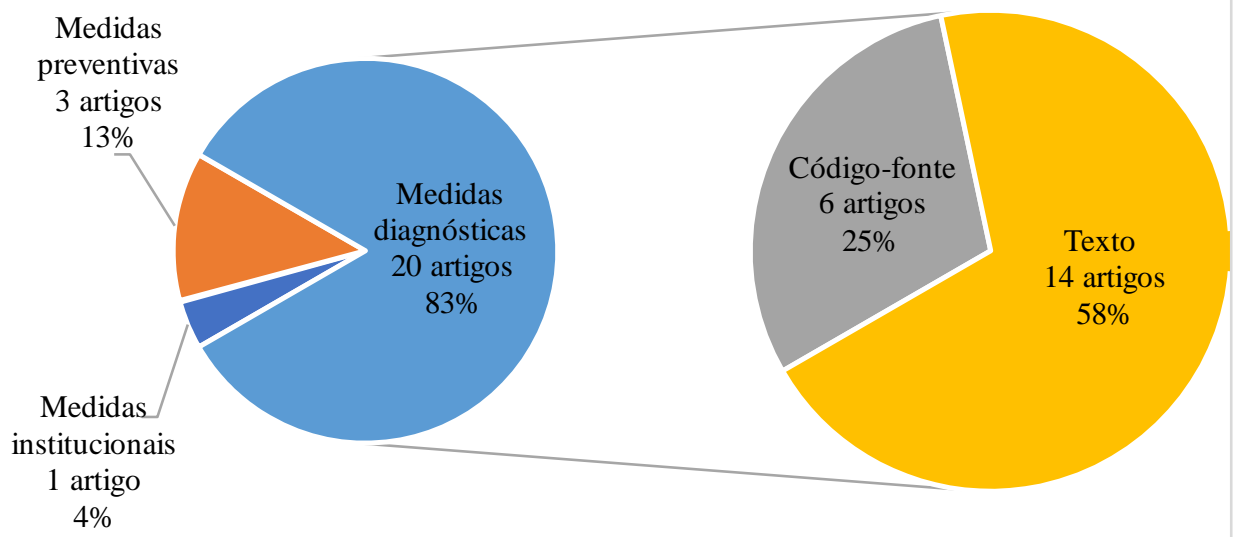

Figura 3 - Estratégias de combate ao plágio adotadas nos artigos selecionados.

Os artigos que utilizavam como estratégia medidas diagnósticas - detecção (19 artigos), obtivemos 13 estudos que utilizavam programas para detecção de plágio em textos $[2,5,9,11,13,15,30,34,41,45,46,52,49], 6$ estudos utilizavam a detecção de similaridade nos códigos-fonte de programas escritos pelos alunos [6,20,24,29,39,42] e 1 estudo utilizou a detecção de plágio em texto manualmente, analisando a escrita. Em seguida, dos artigos selecionados, 3 artigos adotaram medidas preventivas [26,32,49], dos quais um estudo abordava ações de orientação, workshop [49], outro abordava ações de capacitação: elaboração de manuais sobre o assunto [26] e um estudo abordava ações de formação: voltadas para a importância do desenvolvimento de princípios éticos com os alunos [32]. Por último, obtivemos 1 artigo que adotou medidas institucionais, abordando sites institucionais contendo informações sobre plágio, cartilhas e manuais oficiais sobre o assunto [3].

Análise e discussão: Poucos estudos têm sido reportados na literatura científica envolvendo o processo de ensino sobre o plágio em um ambiente educacional brasileiro e sobre novas metodologias de ensino-aprendizagem que visem o seu combate e prevenção. Embora a detecção por software (medida mais reportada nos artigos analisados na RSL) possa ajudar a economizar tempo de trabalho valioso dos professores, ela não poderá ser a única medida válida para a identificação do plágio, já que é necessária a intervenção dos professores para analisar as semelhanças apontadas pelos softwares de detecção. Além disso, o plágio pode ser atribuído à falta de conhecimento dos alunos qu e, muitas vezes, são incapazes de distinguir entre texto plagiado e parafraseado, por exemplo. Sendo assim, a existência de processos metodológicos de ensino que incluam o aprendizado sobre o plágio são de extrema importância para o seu combate, devendo haver, portanto, a necessidade de estudos que retratem e analisem o plágio nessa perspectiva educacional.

QP4: Quais são as vantagens, desvantagens e problemas, em relação às estratégias para combater o plágio acadêmico que vêm sendo reportados na literatur a?

Resultados: Dentre os 59 artigos analisados houveram poucos artigos que descreviam vantagens (5 artigos, 8,5\%), desvantagens ( 2 artigos, 3,4\%) e problemas (7 artigos, $12,3 \%)$ em relação as estratégias utilizadas no combate ao plágio acadêmico. Das vantagens, encontradas nos artigos relacionados às medidas diagnósticas (detecção) [11,49,52], podemos citar estudos que: utilizam o software de detecção com o intuito de reeducar os alunos, conscientizando-o sobre a gravidade [52] e; visam a diminuição do nível de similaridade, com a utilização do software de detecção, pois os alunos são motivados a escrever com originalidade [11]. Em outros dois estudos, cita-se a eficácia 
na detecção, que auxilia o professor no diagnóstico e no controle do plágio entre o s alunos $[13,29]$. Com relação às medidas preventivas, voltadas para o ensino do que constitui o plágio, as vantagens relatadas foram os resultados satisfatórios verificados após os alunos passarem por algum tipo de capacitação acerca do que é plágio e a ut ilização das normas da ABNT [49]. As desvantagens, relatadas nos artigos selecionados em relação às medidas diagnósticas (detecção), foram: software Sherlock, incapacidade de verificar plágio em substituição de palavras por sinônimos ou por não possuírem caracteres especiais latinos [30]. Outras desvantagens encontradas foram que, nos estudos que utilizavam como estratégia medidas institucionais (páginas institucionais com conteúdo sobre plágio, disponibilização de manuais e/ou documentos), não há uma boa comunicação que envolva uma definição clara, uma orientação específica sobre o que é o problema, os motivos que levam a sua ocorrência e orientações gerais de como agir para não estimular a prática do plágio $[3,26]$. Os problemas, encontrados nos estudos em relação as medidas diagnósticas, foram: as ferramentas de detecção não podem ser usadas sozinhas, é preciso a intervenção e avaliação cuidadosa dos dois textos envolvidos antes de acusar o plágio [30]; falta de ferramentas de detecção de uso gratuito [5,4 1]; em determinado estudo, que utiliza detecção de código-fonte, é relatado que, embora a detecção de plágio seja um aspecto importante em cursos de programação, a similaridade de código fonte pode indicar parceria, trabalho colaborativo, referência, e, po r esta razão, naquele estudo, não é adotada a expressão plágio [39]; também em relação à detecção de código-fonte, foi relatado que não é possível padronizar um software ou linguagem de programação para serem usados em uma disciplina de um modo geral, por todos os professores [24]; outro estudo relata o papel das bibliotecas brasileiras em relação ao plágio, havendo poucas informações disponíveis em suas páginas que retratem ações a respeito de plágio e aspectos éticos [3]. Por fim, em relação aos problemas a serem solucionados na utilização das medidas institucionais, é relatado, em um estudo, a necessidade de aprofundar e definir o que é o plágio no país e as diferenças da visão predominante na publicação internacional [26].

Análise e discussão: Os resultados obtidos têm apontado que o combate ao plágio deve ser abordado por meio de uma combinação de medidas e alternativas para ser mais eficiente. Apesar de facilitar e agilizar a maneira de verificar os trabalhos dos alunos, a detecção de plágio por software não pode ser o único indicador utilizado, sendo necessário que o professor analise os trabalhos dos alunos e as semelhanças de textos encontrados pelas ferramentas de detecção, além do que, os softwares de detecção não ajudam diretamente no desenvolvimento do conhecimento do aluno sobre o que constitui o plágio ou sua capacidade de fazer uma citação correta. Com relação ao ensino sobre o que constitui o plágio, através dos resultados obtidos, observamos que há várias vantagens. Os estudos mostram que educar os alunos sobre integridade acadêmica pode ajudar a reduzir a incidência de plágio. A educação tem um foco mais positivo em relação às estratégias de detecção e penalização, e mais apropriada, pois combina a conscientização, orientação e formação, sendo, portanto, uma alternativa mais condizente com a finalidade das instituições de ensino. Os manuais e páginas web, contendo informações acerca de plágio, podem ser úteis se divulgados de forma consistente e persistente ao longo dos cursos. Porém eles sozinhos não possuem eficácia, são necessários o apoio educacional e de infraestrutura para sua implementação e aceitação na prática acadêmica.

\section{Conclusão}

Esta RSL mostrou que o tema plágio no meio educacional vem sendo abordado em vários estudos nos últimos anos no Brasil. Podemos afirmar que o plágio somente tem 
sido tratado na literatura científica preponderantemente no ensino superior, indicando que o aluno começa a aprender ou a se preocupar com o plágio somente quando ingressa na graduação. A análise dos estudos ainda mostrou que há várias estratégias adotadas no combate ao plágio, contudo, a estratégia de detecção de plágio foi a mais utilizada, havendo poucos estudos envolvendo o processo de ensino sobre o plágio em um ambiente educacional brasileiro e sobre metodologias de ensino-aprendizagem que incorporem e aliem o seu combate com a sua prevenção. Além disso, verificou-se que não houve nenhum estudo reportando o uso de ferramentas computacionais que tenham sido desenvolvidas especificamente para auxiliar o ensino sobre plágio. Concluímos, portanto, que há grande carência no desenvolvimento de novas aplicações envolvendo o tema, como ferramentas que ajudem a diminuir os casos de plágio e contribuam na formação ética de cada aluno.

\section{Referências Bibliográficas}

CNPq. Diretrizes - Portal CNPq. Disponível em <http://www.cnpq.br/web/guest/diretrizes>. Acesso em: 12 de mar. 2019.

DE OLIVEIRA ARAÚJO, Elani Regis. $O$ plágio na pesquisa científica do ensino superior. Pesquisa Brasileira em Ciência da Informação e Biblioteconomia, v. 12, n. 2, 2017.

FAPESP. Código de boas práticas científicas. São Paulo: FAPESP, 2014. Disponível em: <http://www.fapesp.br/boaspraticas/FAPESP-Codigo_de_Boas_Praticas_Cientificas_2 014.pdf>. Acesso em: 12 de mar. 2019.

GIL, Antonio Carlos. Como elaborar projetos de pesquisa. 6. Rio de Janeiro: Atlas, 2017.

GIL, Antonio Carlos. Estudo de caso: fundamentação científica; subsídios para coleta e análise de dados; como redigir o relatório. São Paulo: Atlas, 2009.

INFORMAÇÃO \& SOCIEDADE: ESTUDOS. Base de dados I\&S: no ar desde 1991. Disponível em: < http://www.periodicos.ufpb.br/index.php/ies/>. Acesso em: 12 de mar. 2019.

JOURNAL OF HEALTH INFORMATICS. Base de dados JHI: no ar desde 2012. Disponível em: 〈http://www.jhi-sbis.saude.ws/ojs-jhi/index.php/jhi-sbis>. Acesso em: 12 de mar. 2019.

KITCHENHAM, Barbara; CHARTERS, Stuart. Guidelines for performing systematic literature reviews in software engineering. EBSE Technical Report. 2007. Disponível em: <https://elsevier.com/__data/promis_misc/525444systematicreviewsguide.pdf >. Acesso em: 12 de mar. 2019.

KROKOSCZ, Marcelo. Outras palavras: análise dos conceitos de autoria e plágio na produção textual científica no contexto pós-moderno. 2014. Tese de Doutorado. Universidade de São Paulo.

KROKOSCZ, Marcelo. Abordagem do plágio nas três melhores universidades de cada um dos cinco continentes e do Brasil. Revista brasileira de educação, v. 16, n. 48, p. 745-818, 2011.

MARTINS, Luiz Eduardo G.; GORSCHEK, Tony. Requirements engineering for safety-critical systems: A systematic literature review. Information and software technology, v. 75, p. 71-89, 2016.

NERY, Guilherme et al. Nem tudo que parece é plágio: cartilha sobre plágio acadêmico. Instituto de Arte e Comunicação Social da Universidade Federal Fluminense-UFF, Rio de Janeiro/RJ, 2010.

PORTAL DE PERIÓDICOS CAPES/MEC. Base de dados CAPES: no ar desde 2000. Disponível em: <http://www.periodicos.capes.gov.br/>. Acesso em: 12 de mar. 2019. 
REVISTA BIOÉTICA. Base de dados Rev.bioet.: no ar desde 1993. Disponível em: < http://revistabioetica.cfm.org.br/index.php/revista_bioetica/>. Acesso em: 12 de mar. 2019.

REVISTA BRASILEIRA DE APRENDIZAGEM ABERTA E A DISTÂNCIA. Base de dados RBAAD: no ar desde 2002. Disponível em: < http://seer.abed.net.br/index.php/RBAAD/>. Acesso em: 12 de mar. 2019.

REVISTA BRASILEIRA DE EDUCAÇÃO. Base de Dados Redalyc: no ar desde 2002. Disponível em: <https://www.redalyc.org/revista.oa?id=275>. Acesso em: 12 de mar. 2019.

REVISTA BRASILEIRA DE ENSINO DE CIÊNCIA E TECNOLOGIA. Base de Dados RBECT: no ar desde 2008. Disponível em: <https://revistas.utfpr.edu.br/rbect/>. Acesso em: 12 de mar. 2019.

REVISTA BRASILEIRA DE INFORMÁTICA NA EDUCAÇÃO. Base de Dados Redalyc: no ar desde 1997. Disponível em: < http://www.br-ie.org/pub/index.php/rbie>. Acesso em: 12 de mar. 2019.

REVISTA CONHECIMENTO EM AÇÃO. Base de Dados BRAPCI: no ar desde 2016. Disponível em: <https://revistas.ufrj.br/index.php/rca〉. Acesso em: 12 de mar. 2019.

REVISTA DE DIREITO, INOVAÇÃO, PROPRIEDADE INTELECTUAL E CONCORRÊNCIA. Base de Dados RDIPIC: no ar desde 2015. Disponível em: < https://www.indexlaw.org/index.php/revistadipic/>. Acesso em: 12 de mar. 2019.

REVISTA ELETRÔNICA EM GESTÃO, EDUCAÇÃO E TECNOLOGIA AMBIENTAL. Base de Dados REGET: no ar desde 2010. Disponível em: < https://periodicos.ufsm.br/index.php/reget>. Acesso em: 12 de mar. 2019.

REVISTA NOVAS TECNOLOGIAS NA EDUCAÇÃO. Base de Dados RENOTE: no ar desde 2003. Disponível em: <https://seer.ufrgs.br/renote/>. Acesso em: 12 de mar. 2019.

REVISTA PONTO DE ACESSO. Base de Dados PontodeAcesso: no ar desde 2007. Disponível em: <https://portalseer.ufba.br/index.php/revistaici>. Acesso em: 12 de mar. 2019.

REVISTA TEMPOS E ESPAÇOS EM EDUCAÇÃO. Base de dados revtee: no ar desde 2002. Disponível em: <https://seer.ufs.br/index.php/revtee/>. Acesso em: 12 de mar. 2019.

SIMPÓSIO BRASILEIRO DE INFORMÁTICA NA EDUCAÇÃO. Base de Dados SBIE: no ar desde 1990. Disponível em: < http://www.br-ie.org/pub/index.php/sbie/index>. Acesso em: 12 de mar. 2019.

UNTERKALMSTEINER, Michael et al. Evaluation and measurement of software process improvement - a systematic literature review. IEEE Transactions on Software Engineering, v. 38, n. 2, p. 398-424, 2012.

VILAÇA, MURILO. Más condutas científicas uma abordagem crítico-comparativa para informar uma reflexão sobre o tema. Revista brasileira de educação, v. 20, n. 60, p. 245-269, 2015.

WORKSHOP DE DESAFIOS DA COMPUTAÇÃO APLICADA À EDUCAÇÃO. Base de Dados Desafie: no ar desde 2012. Disponível em: < http://www.brie.org/pub/index.php/desafie/index>. Acesso em: 12 de mar. 2019.

WORKSHOP DE INFOMÁTICA NA ESCOLA. Base de Dados WIE: no ar desde 1995. Disponível em: < http://www.br-ie.org/pub/index.php/wie/index>. Acesso em: 12 de mar. 2019.

WORKSHOPS DO CONGRESSO BRASILEIRO DE INFORMÁTICA NA EDUCAÇÃO. Base de dados Workshops do CBIE: no ar desde 2012. Disponível em: < http://www.brie.org/pub/index.php/wcbie/>. Acesso em: 12 de mar. 2019.

YIN, Robert K. Estudo de Caso-: Planejamento e métodos. Bookman editora, 2015. 